\title{
The Roseires Dam, Sudan: planning and design
}

\author{
R. L. FITT, R. MARWICK \& F. W. A. WHITAKER \\ The Roseires Dam, Sudan: construction
}

\author{
R. L. FITT \& J. V. CORNEY
}

\section{Mr R. G. T. Lane, Sir Alexander Gibb \& Partners}

With a scheme of this kind there are many problems associated with its size, but as a dam problem, it is of moderate scale in regard to the height of its various elements. Nevertheless, there were one or two technical aspects which are interesting and perhaps unique. First of all, there is the question of the clay foundation. A typical vertical section in this clay showed slickensides, normally at an angle of about $45^{\circ}$ to the vertical in all directions, criss-cross, and about 5-6 in, in length. It does seem to me that such slickensides are there as a result of stress.

2. In $\S 46$ of Paper 7047 the Authors refer to the clay as being over-consolidated by desiccation. I do not quite understand what this means, but would suggest a possible explanation. According to the geologists, this clay plane once had a surface many metres - 100 or more-higher than the present level, and the clay was therefore under a considerable vertical pressure. Since then, the vertical pressure has been reduced in comparison with the horizontal pressure. Recent studies throughout the world have indicated that the surface of the earth is under very high horizontal compression. The clay on which the dam is founded may already be in a state of considerable horizontal pressure, enough to have caused fissuring of the clay on removal of the vertical load, and there remains in the clay a horizontal pressure which is the maximum that it will take now that it has in fact failed.

3. From reference to $\S 54$ of Paper 7047 it will be realized, I suggest, that there is still uncertainty as to whether one should design for the minimum ultimate strength of clay or something greater, and it would seem to me appropriate in a case like this also to take account of the fact that the clay on which the dam is founded is already in horizontal compression.

4. The second point of great technical interest relates to the deep sluices. Here the velocity of the water is high, and we were very concerned in regard to the specification for the concrete, to resist the forces which would apply--possibly cavitation, and certainly with silt and sand a certain amount of erosion. The conclusion was reached, confirmed by abrasion tests, that the hardest aggregate we could get should be used. Granite was definitely harder than the marble. We tried to make the mortar as hard as the granite, but did not quite succeed.

5. During one flood season the sluices operated as free temporary openings. Considerable bed-load of sand and gravel passed through, particularly at sluice No. 5 when the invert was eroded to a rough surface with the aggregate exposed. The next season was the first year of operation of the dam and the flood was passed through the sluices, controlled by operation of the gates. After the flood, an inspection by diver was carried out and it was found that there were small areas of erosion. The area was then cofferdammed and de-watered and we found places where the surface had either been slightly worn or small pockets had been formed.

6. Fig. D1 shows the patches being cut out ready for placing new concrete. A pile of stones will be noticed. Some of them were as long as $\frac{1}{2} \mathrm{~m}$ or more. We 


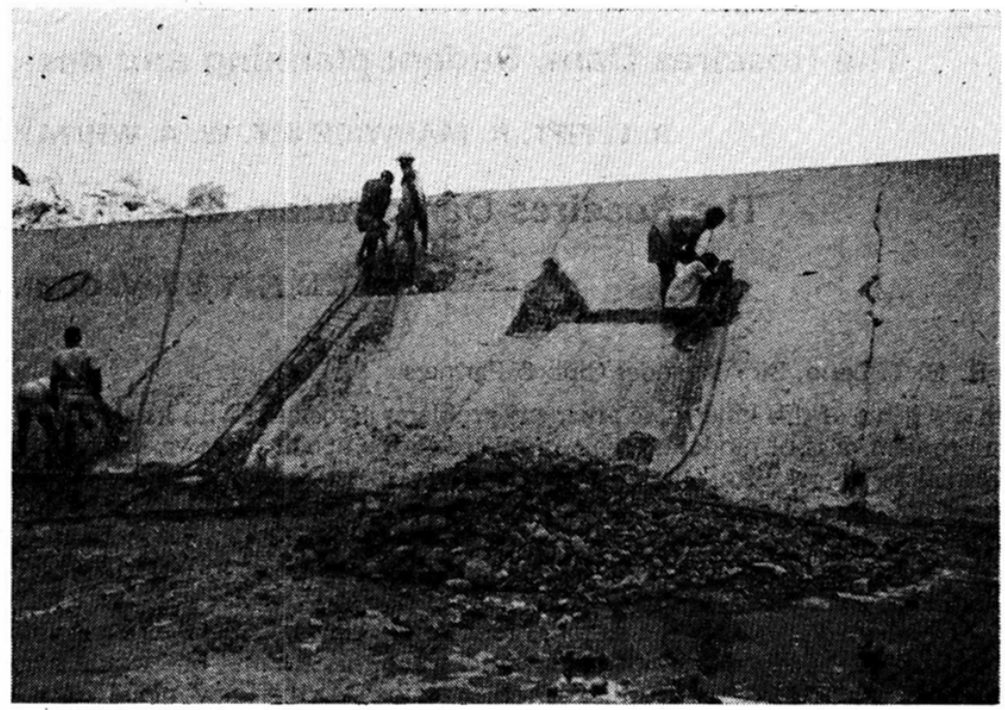

Fig. D1

wondered how they had got there because we had satisfied ourselves on the model that the prescribed method of operation of the gates would not allow material from downstream to come back. We then carried out further tests and found that a transient condition could arise as the gates were closed which allowed material to come over the kicker, all within a period of only a few minutes. It was necessary to close the gates in the right order to avoid this.

7. The third point relates to design. It will be noticed that the buttresses appear thin compared with the height of the dam. We have achieved, under the worst possible conditions, a sliding factor of 0.9 . Have we, as dam designers, reached the ultimate in economy in the use of concrete in a dam relying on gravity for stability?

8. Finally, reference is made in the Paper to instrumentation. There are very good reasons for the instrumentation which is put into Roseires Dam, particularly in relation to the behaviour of the dam constructed on black cotton soil. Also, the dam is to be raised, and it is necessary to know as much as possible of its behaviour. But I would make the point that the movements being recorded are all very small. In the general case, should not the instrumentation of a dam of this height be kept to the minimum necessary to watch general behaviour? When the movements are so small it is difficult to separate the effects of the many different factors which cause movement.

\section{G. Schmidt, Chief Engineer, Coyne et Belliér}

It is now twelve years since our firm started to work together with Sir Alexander Gibb and Partners on the Roseires Dam project and since, in the company of the late André Coyne, I paid what was for me the first of a long series of visits to London and the Sudan for technical meetings with our British associates and friends.

10. This long collaboration was, I feel, a very fruitful one for the project and for many of those who participated in it on both sides, for the good reason that discussion was made more enlightening by, on the one hand, the common high sense of the 
consulting engineer's responsibilities and duties and, on the other, the appreciably different approaches to actual design and practical problems and somewhat different backgrounds of experience. Although, over a few details, debatable design compromises may have arisen, nevertheless this combination of the two firms' experience was on the whole most rewarding. And it is indeed quite a landmark in this second half of the twentieth century to see this joint achievement of the British and the French in the service of the Sudan when, seventy years ago, they were dreaming of this part of Africa in rather opposing ways.

11. With the adjustment to each other's particular type of marked national character--an increasing necessity in our modern world---one of the most noticeable aspects of the Roseires Dam project was the close adaptation of its design and method of construction to the singular natural features as they appeared. This could only be achieved at the construction stage by close liaison and co-operation between the design offices and the site.

12. This very careful adaptation is particularly reflected in:

(a) the selection of the site for the dam;

(b) the detailed layout of the dam as a whole taking account of the particular requirements of each structure in view of their hydraulic functions;

(c) the selection of the operating pattern for the project;

(d) the manner of dealing with foundation problems in each particular section;

(e) the very extensive use of as-raised local materials for the embankment dams;

$(f)$ the realistic account taken from the outset in all aspects of the design and construction programme of the very particular climatic and river conditions.

13. It is a great pleasure for me to conclude these few words by drawing attention to the fact that this $\mathbf{1 5}$ year long project, of which he was the constantly very active and tactful head, has been for Mr Fitt a fitting climax to a career which was initiated some $\mathbf{4 0}$ years ago in the Sudan Gezira.

\section{Mr D. J. Knight, Sir Alexander Gibb \& Partners}

I should like to comment on the relationship between investigation, design and construction at Roseires, as seen from the point of view of the design staff.

15. First, a reminder is perhaps appropriate on the difference in design philosophy pertaining to traffic-bearing and water-retaining embankments. Casagrande, ${ }^{\mathrm{D} 1}$ in discussing the failure of the Great Salt Lake Railroad fill, recalled that 'An engineer who had extensive experience in building long highway embankments on soft clay once remarked that if no failure occurs it proves to him that the embankment was overdesigned'. He was, of course, depending on the increase of strength of normally consolidated clays under load, but the contrast is still relevant. No failure can be tolerated in a water-retaining structure.

16. A retrospective view of the past five years permits identification of the key factors in the design development of the Roseires earth embankments. When one is at the beginning of a job various obvious steps to be taken form an initial plan of campaign. First comes the general reconnaissance of the site, to provide an overall picture. This is followed by a more detailed examination of representative elements in that picture, chosen so that as far as can be foreseen they will cover the different problens likely to arise. Alongside such investigations a reasonable working hypothesis is adopted which is changed as necessitated by their results. At Roseires the 'general reconnaissance' was carried out in 1953/54, as a soil survey of foundations and borrow areas. In 1962 the final alignment of the dam was decided. At this stage entered the first key factor in the development of the ultimate design, namely, the scope and timing of the comprehensive foundation investigations, as illustrated on Fig. D2. These were required to extend the original investigations, which covered the higher parts of the dam only, and to provide effective stress parameters for design. 


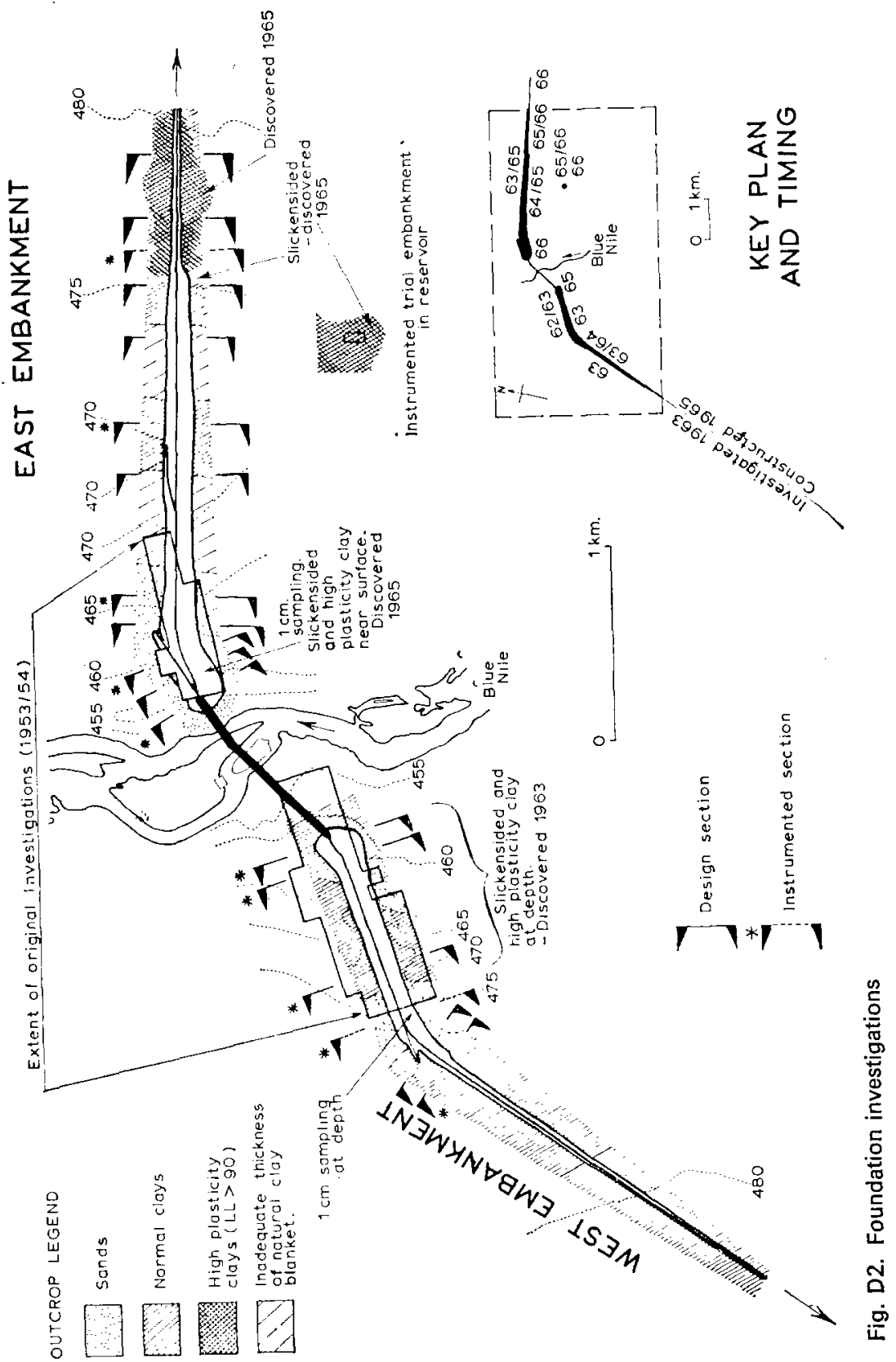


These additional investigations began towards the end of 1962, as part of the Main Contract, and over the years helped eventually to provide hundreds of boreholes and test pits over the foundation areas. Meanwhile, it was necessary to adopt preliminary design parameters to enable design work to proceed for the high section of the west embankment. The first decision required here concerned the contract drawing provision of an artificial upstream blanket, for seepage control where the dam crosses a pervious outcrop. Study of alternative designs showed that a positive cut-off to the lower clay could be provided more economically and this solution was adopted. By its excavation in March 1963 full-scale work thus started alongside the foundation investigations.

17. The second key factor was the discovery of significantly different properties of some of the foundation clays to those revealed originally. High plasticity clays had already been discovered during the construction of the airfield and township roads. Now, soon after the dam site investigations had started, such clays were again found to be more plastic than those studied in 1953. Furthermore, a few weeks before construction began slickensides were discovered in one of the early test pits dug into the lower clay on the west bank and soon afterwards were revealed in the cut-off trench. In retrospect it can be seen that if the cut-off substitution had not been made the slickensided nature of the clay might not have been confirmed so convincingly. Thus previously unknown facts about the foundations were coming to light during construction.

18. The third, and most fundamental, factor in the design development was the doubt about the long-term shear strength of the foundation clays, whether the normal or the very high plasticity material. This had a profound effect on the design work, which, instead of being able to proceed on the basis of available and valid test results, had to take into account possible lower strengths resulting from a new series of tests yet to be devised. Design stability analysis had to cover Stage 2 heightening for the upstream slope and Stage 1 level for the downstream slope, different heights and foundation conditions, different possibilities for the outcome of tests for foundation and fill shear strength parameters, and different internal arrangements of features and materials, according to their availability, suitability and overall economics. At the same time analysis had to be adequate for any particular combination of these variables. By October 1963 sufficient test results were available from which to decide final design parameters. After discussion with Professors Skempton and Bishop safety factors were increased. Angles of shearing resistance were also increased from the conservatively low values that had been adopted as an interim measure.

19. Thus from the outset of working design and construction a process of discovery, evaluation, decision and execution began which continued virtually throughout the ensuing four years, as again illustrated on Fig. D2; the initial discoveries of the existence of slickensides and very high plasticity clays in the first $1.3 \mathrm{~km}$ of the west bank acted as a constant reminder for vigilance during the investigations for the remaining $11.2 \mathrm{~km}$, of which $4.0 \mathrm{~km}$ were on the opposite bank. As Paper 7047 stated in $\S 55$, 'it was feared that the most highly plastic clay, which appeared to occur as isolated lenses, might constitute thin but continuous horizontal deposits... Sampling at $1 \mathrm{~cm}$ intervals in pairs of pits failed to substantiate this fear in all except one area of a thick continuous desposit'. It is instructive to recall how in fact it was discovered that the east intermediate section crossed such a deposit. We wished to follow up the indications of these pits with more local investigations, but the question was: where? It was our standard procedure to test the materials through which holes were drilled for the installation of permanent standpipe piezometers, which are a part of the general earth dam instrumentation system. One such piezometer was noticed to have passed through high liquid limit clays at about the middle of the east intermediate section, the highest value of liquid limit being $123 \%$. Previous investigations in the general area had not revealed more than the upper range of the normal clay. It was suggested, therefore, that that might be a suitable starting point for extending 
the search for high plasticity clay. Consequently, rings of boreholes were put down centred on this spot, starting at a radius of $5 \mathrm{~m}$ and, as the existence of highly plastic clay was confirmed, at successive radii of $25 \mathrm{~m}, 50 \mathrm{~m}, 100 \mathrm{~m}$ and $200 \mathrm{~m}$. The outcome was positive in establishing that the entire east intermediate section, just under $1 \mathrm{~km}$ in length, lay on such clay, and it was accordingly redesigned for a residual $\phi^{\prime}=15^{\circ}$ as compared with $19^{\circ}$ for the normal clay.

20. Slickensides were also discovered during excavation for the highest part of the earth dam, at the east transition with the concrete dam, necessitating further checking of the design almost at the end of construction.

21. What lessons can be drawn from such experiences? The first is that of the need for continual vigilance throughout the whole process of investigation-in both its planning and execution-and of construction. This means the careful observation on site and reporting of anything unusual to the designers. The second lesson, of equal importance, is the necessity for appropriate action to be taken on the basis of such reports, not ignoring the slightest hint of poor conditions. Finally, after the dam is built and is in operation, it is essential that its behaviour be regularly and thoroughly observed, both visually and by means of an adequate installation of survey points and instrumentation. These points have been made before and will no doubt be made again. Nevertheless, examples of their relevance should contribute to the taking of increased care in such matters, essential if the seemingly conflicting requirements of safety and economy are to be harmonized.

\section{Mr F. Antonioli, Impregilo, Milan}

As indicated in Paper 7048, we as Contractors realized from the very beginning that it might be possible to complete the work in five instead of six years. We therefore decided to design our installations and to establish our organization and programme the construction works so as to achieve the desired speed.

23. The following figures may give an idea of the effort involved. The constructional plant and the equipment brought to the site were valued at just over $£ 2$ million. The number of European workers employed at Roseires was over 250. The staff was about 120, comprising 90 Europeans and 30 Sudanese. The Sudanese labour force reached a maximum of over 2500 . Recourse to overtime was necessary, and it was considerable during almost the whole duration of the works.

24. The climatic conditions were severe and the temperature rather trying, but the housing accommodation was comfortable, and this proved very useful in keeping the workers from abroad happy, especially those who had brought their families.

25. Our company is known to attract unprecedented floods! I do not want to miss this opportunity therefore, to improve our reputation among clients, engineers and insurance companies by saying that the Blue Nile has been very kind to us.

26. Our difficulties at Roseires did not come from the river; they were more logistic problems. Roseires is 700 miles away from Port Sudan, the only port of entry for equipment and materials, and this distance is only covered by a railway which is exposed to severe summer weather. From July to September the road connecting Wad Medani with Roseires becomes impassable and the possibility of supplying the site virtually disappears for three months. In fact, we had to discontinue our work every summer and this brought about serious disruption in our organization. Roseires is a remote place and we had to obviate this by devoting special care to the problems of welfare and recreation. We who have worked there, however, have very good memories of our five years at Roseires. This is largely due to the pleasant atmosphere of our relationships with the Sudanese people and authorities.

27. Finally, I wish to express, on behalf of the Board of my Company, our appreciation of the friendly relations we have had with British engineers, and the hope that there will be many new opportunities to co-operate with them in the future. 


\section{Mr B. T. Seddon, Binnie and Partners}

With regard to the design and construction of the buttress dam, it is interesting to note that the maximum theoretical principal compressive stress in the buttresses is $31 \mathrm{~kg} / \mathrm{sq}$. cm, which is nearly double the maximum stress in some of the earlier Scottish buttress dams, although the cement content appears to be increased by only about $15 \%$. This indicates a useful saving in cost. On the other hand, reinforcement has been introduced, which from my recollection is unusual in the Scottish dams. It would be useful if the Authors could say a little about this. Swedish practice is to reinforce the upstream face with a mesh of $19-22 \mathrm{~mm}$ bars at $400 \mathrm{~mm}$ spacing. What was the spacing that the Authors adopted? The recess between the buttresses is presumably introduced to compress the head of each buttress, but it is not quite so clear what the distribution of stress would be downstream of the bitumen seal. Could the Authors say something about the general stress distribution in the buttress heads? Also what was the maximum compressive stress of the upstream face with the reservoir fill and what uplift assumptions were made in design?

29. Certain buttress dams have quite elaborate splays at the downstream toes to reduce theoretical stress concentrations at changes in sections. The Authors have simplified the shuttering by stepping the sections and avoiding splays. Did they take the view that splays were unnecessary or would they introduce them on a higher dam?

30. There seems to be some evidence that it is advisable to reduce the height of lift when pouring concrete onto existing concrete which is more than about three months old. If this is not done there may be a danger that shrinkage stresses will be introduced at the construction joint to such an extent that the bond may be broken. For these reasons it has been usual, when raising a concrete dam by placing a slab on the downstream face, to separate the slab from the body of the existing structure. It would appear that gaps of three or four months or more arose at Roseires during the wet season. What were the Authors' views on this point? Did they feel that there was any need to reduce the height of lift or was the fact that they had put reinforcement on the upstream face of the buttress sufficient?

31. I note that the cement content was adjusted during the Contract to maintain the average cube strength. How was this paid for? Was the cement paid for separately from the concrete and was the mix. designed by the Engineer, or by the Contractor to meet certain requirements laid down by the Engineer?

32. The emergency gates upstream of the deep sluices are provided with a $\mathbf{4 2 0}$ ton hoist capable of cracking open a gate. It seems a little unusual to have two gates on one opening both capable of opening under unbalanced pressure, and one notes that the upstream gate is not provided with any protection downstream of the gate body.

\section{Mr A. D. M. Penman, Building Research Station}

I am stirred to make a few remarks after hearing Mr Lane, who seemed to be against the use of instrumentation for the dam. It has come out in the discussion that in the design of an earth-filled dam it is very difficult to arrive at final conditions from the initial site investigation, and really it is only when the borrow pits have been opened up and some work has been done for the foundation that the true condition of the soil comes to light. I think this has also been shown by the change in design which took place after work had started at Roseires in the early 1960's. In conditions like these it means that we do not really know what we are doing in the design of the dam in the early stages. The least one can do is to attempt to correlate the final behaviour of the dam with the design assumptions by some observations of its behaviour by building in some sort of instrumentation. For this reason I feel that people should not begrudge the money spent on instrumentation; it is only in this way that there is any opportunity for improving design or for seeing that the design procedures adopted are safe ones. 


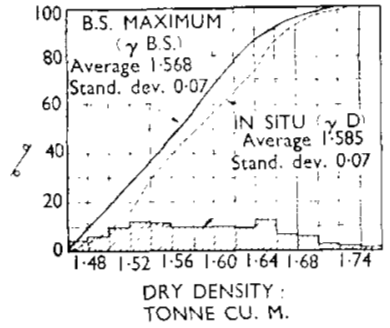

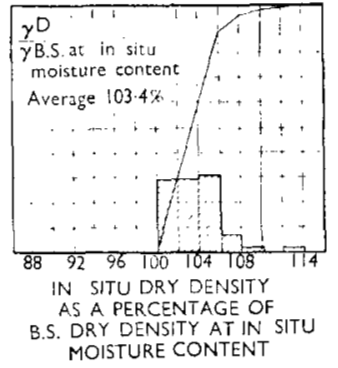

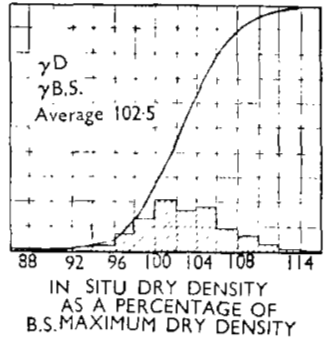

Fig. D3. Zone A clay densities: typical summaries

34. I would like to ask the Authors if it would be possible for them to work out the actual expenditure on instrumentation at Roseires. It is mentioned in the Paper that because of lack of funds it had to be limited and I would be interested to know, if not an actual figure, then the percentage of the cost of the total work.

\section{Mr W. E. Blackmore, Sir William Haicrow and Partners}

In $\S 10$ of Paper 7047 the Authors say that 'the dam has been designed to pass 17600 cumecs with all gates fully open and with a reseryoir level of $481 \mathrm{~m}$.' This level is in fact practically the crest level not only of the concrete dam but also of the embankment dam. Would the dam remain safe if the gates failed to open when a flood came? I assume that they are electrically operated and that electricity is, or will be, available either from the power station at the dam, which may not be operative in a flood, or from another source which must be a long way away and vulnerable. If a failure of electricity coincided with a flood would the gates remain immobilized and would the water level thereby attained create a threat to the dam?

\section{Mr R. A. Matthews, Sir Alexander Gibb and Partners}

The single point method of density control is mentioned in $\S 62$ of Paper 7048 , and as this was a fairly successful method of control $I$ think it is worth explaining in a little detail. It is in fact a good example of M. Schmidt's remarks earlier about consultation between ourselves and our French colleagues as this was first put into operation by M. Le Moigne of Coyne et Béllier and eventually became the standard control for the clay core of the embankments.

37. The basic problem was that at Roseires the black cotton clay had very random variations in density and it was therefore impossible to lay down a field density requirement fixed by B.S. compaction tests from borrow pit samples.

38. Instead of comparing the in situ density with the B.S. maximum density a single point is obtained on the compaction curve on site without any adjustment to the moisture content, so that one gets the B.S. compaction at that moisture content. The method of control was to drive the core cutter to take out with it enough soil to do a full B.S. compaction test, and also one extra point. The full sample was sent to one of the main laboratories; the small sample for the extra point was sent with the core cutter to a small site hut, within easy reach of the placing area. The results of the in situ density and the single point were available within half an hour of the samples being taken and a decision on whether to re-roll the area or to approve it was based on these results, by requiring the in situ density to be at least $100 \%$ of the single point density. 
39. Figure D3 shows the wide variation of the in situ densities of the black cotton clays, from 1.47 to about 1.75 tonnes $/ \mathrm{cu}$. $\mathrm{m}$. It can be seen from the shape of the curves, which are very similar, that the spread of B.S. compaction results was as wide as the in situ results, which confirms that it would have been quite impossible to lay down a specific density as a target density.

40. In order to check that the system was working the full B.S. compaction tests were carried out in one or other of the main laboratories and a summary regularly produced to show what percentage of the B.S. compaction was being achieved. In this batch the average was $102.5 \%$, and about $10 \%$ had densities lower than $98 \%$ of the B.S. maximum. For an earth embankment this was regarded as quite satisfactory. I am not suggesting that this is a satisfactory method of control generally for earthworks but at Roseires it did provide a very quick method, it gave reliable results, and it also provided sufficient statistical data for use in the Stage 2 design.

\section{Mr A. K. Macdonald, Binnie and Partners}

I would like to refer to $\S 80$ of the Paper 7048 , dealing with the collimation lines and inverted pendulums. Could the Authors say a little more about the inverted pendulums, in particular how deep they went in to bedrock, and whether they came right up to the crest or very nearly to the crest of the monoliths? There would appear to be some difficulty in getting a pendulum right through the buttress and crest. If there is only one pendulum at a section it seems that there is difficulty in distinguishing between movements in the bedrock and tilting movements purely in the concrete. Do the Authors consider this distinction to be of importance?

42. In $\S 83$ it is stated that the triangulation had an accuracy within $1 \mathrm{~mm}$. This figure is surprisingly small. The distances from the fixing stations are not given but from Fig. $16 \mathrm{I}$ estimate that they must be about $260 \mathrm{~m}$ back from the dam. If it is only $200 \mathrm{~m}$ it would seem that the fixing station is itself somewhat liable to movements or distortions due to water loading.

43. With regard to $\$ 88$, and Fig. 18, the fixing stations for the earth embankments are about $500 \mathrm{~m}$ back from the water faces, which would be about 2 or $2 \frac{1}{2}$ times what is used in the concrete works. There is a mention of 'stiff pipes fixed at the bottom of deep boreholes'. Could the Authors say a little more about these stiff pipes and how the theodolites are related to them?

44. Both in the concrete and earth embankment triangulation schemes there seems to be an absence of a supporting triangulation framework such as is usually provided. The impression is given that if one of the stations a few hundred metres downstream were to be damaged there would not be very much that could be done to check what was going on. Could this be explained, if possible?

Mr H. Dixon. Howard Humphreys and Sons

As a quick check on the density of a rolled embankment I have used the following method. A correlation has been made of dry density against unconfined compressive strength. We have found in the case of a particular clay in Kenya that if these unconfined compressive strengths are $25 \mathrm{lb} / \mathrm{sq}$. in. or higher, the compaction is adequate. If, on the other hand, they fall below this figure, the compaction is inadequate and more passes of the roller have to be given. This is an extremely rapid method of checking compaction but naturally it does not dispense with the standard tests such as sand replacement.

46. I was alarmed to hear earlier in this discussion that instrumentation might be cut down. I agree entirely with Mr Penman that this would be quite undesirable as a generality. There may be particular cases where some economy is permissible, but in general I must say instruments to assess performance are necessary both during construction and in the working life of a dam.

47. I have had to raise the Sasumua Dam during the past two years. The instruments we put in in 1954 are now again in use, and we have been able to check the 
performance of the raised embankment during construction. For this reason alone I am very glad that we had put them in, because in no other way could we have told what was going on both as to pore water pressure and settlement.

Mr N. H. Searle, Central Laboratory, George Wimpey and Co. Ltd

I recall the early site investigation work during which the camp drinking water was taken from the Blue Nile. In the dry season the water was so clear that filters were unnecessary but at the start of the flood, conditions changed rapidly and the river appeared to carry a heavy silt concentration. Appendix 2 of the Paper indicates that Aswan data was used for assessing the effect of future silt deposition in the reservoir. However, at Aswan the river has been joined by the White Nile and other rivers with the result that silt and deposition characteristics may be rather different from those in the upper reaches of the Blue Nile. I wonder why this data was used in preference to information from Sennar Dam on the Blue Nile, built 30 years ago and only a relatively short distance downstream of Roseires.

49. I am also interested in whether the model tests had been used for examining alternative flood structure arrangements, particularly in relation to the reduction of siltation in the reservoir.

\section{Written contributions:}

\section{Mr E. Zolkov, Standards Institution of Israel}

Would the Authors care to comment on the reliability of the 'one point' method of determining maximum B.S. compaction?

51. How frequent were the densities below the recommended minimum, such that they did not 'reduce the mean dry density below the B.S. maximum'?

52. Was an attempt made to formulate specifications on the basis of statistical quality control concepts?

53. The discrepancy between $24 \mathrm{~h}$ oven-dried and short-time gas burner moisture content results is most interesting. The Writer has similar experience, but this was quite definitely largely due to the presence of significant quantities of gypsum in the soils which ranged from SM to ML. The discrepancies ranged from less than $1 \%$ to as much as $5 \%$ ! In such soils the use of nuclear methods to determine moisture content is also únsuitable.

Dr A. K. Biswas, Dept of Civil Engineering. Queen's University, Kingston, Ontario Fitt, Marwick and Whitaker have done a service to the profession by their lucid presentation of the design aspects of a major dam. Having specialized in hydrology and water resources engineering for some time, the Writer's comments are exclusively directed to the design aspects of these subjects.

55. The relationship between the highest recorded peak discharge and the maximum 10 day mean discharge is certainly remarkable. The maximum flow at 10800 cumecs is only about $7 \%$ higher than the 10 day mean discharge of $10078 \mathrm{cu}-$ mecs, which indicates that variation in flow during the period under consideration could not have been much. This at once prompts the questions, what method or methods were used for gauging the river around 1946 and earlier, and what is the opinion of the Authors about their accuracy?

56. In our present state of knowledge it is impossible to define the upper limit of any natural phenomenon ${ }^{D 2-D 5}$ - and flood estimation is no exception. For a major dam like the Roseires which has a catchment area of the order of $210000 \mathrm{sq} . \mathrm{km}$ the problem of fixing the spillway design flood must have been a complex one. Unfortunately not enough information has been provided on the hydrological aspects of the design compared to the meticulous details on the soil mechanics and foundations side-and this is the Writer's only complaint. 
57. For the purpose of the present discussion it will be assumed that the design flood was estimated by using the deterministic concept of the probable maximum precipitation-which is a rather common practice. Having been associated with the problem of estimating the probable maximum flood for major dam designs from scantily available meteorological data, the Writer is convinced that the result is sometimes to be taken with a pinch of salt---especially in the case of big rivers whose drainage areas cover tens of thousands of square miles. There just does not exist enough hydrometeorological information for a reasonable length of time to supply the input data necessary for adequate working of the method. So, finally, the estimation of the probable maximum flood boils down to making an estimate from a series of estimated hydrometeorological parameters.

58. Just to give an example, one of the major meteorological parameters needed to estimate probable maximum precipitation (pmp) is the dew point, and the method used is 'somewhat subjective'. ${ }^{\mathrm{D}}$ Recently the US Weather Bureau has pointed out ${ }^{\mathrm{DT}}$ that the dew point is a random variable and as such does not appear to have a definite upper limit. The procedure is further handicapped by the fact that precipitation increases by about $7 \%$ by a change of one degree of the dew point $;^{D 8 . D 9}$ and such dew points have to be evaluated within a degree or so to be of any quantitative value.

59. The probable maximum flood obtained by using the concept of pmp is after all an estimate, and like any other estimate, it is subject to limitations of data and inaccuracies of methodologies. Different studies, using the same approach and for the same area having the same data, are known to have given very different results. Besides pmp generally indicates a very high value of precipitation, and there have been serious doubts expressed by eminent hydrologists that such a compounding of circumstances is really possible or probable. For example take the case of Urbana in Illinois. The maximum $24 \mathrm{~h}$ rainfall ever recorded is $4.61 \mathrm{in}$. on $25 \mathrm{May}, 1921$; the maximum officially recorded value in the whole state is $11.47 \mathrm{in}$, and the maximum unofficial catch is 16.54 in. Compared to the above figures, the pmp estimate for Urbana is 30.5 in.

60. There has been a growing concern among the hydrologists about the degree of acceptance that should be accorded to pmp. ${ }^{\mathrm{D3}-\mathrm{D} 5, \mathrm{D} 8-\mathrm{D} 19}$. It is also to be realized that the term pmp is a logical and literal inconsistency as a maximum does not have any probability associated with it (only the limiting exceedence probability is zero). The pmp as it is known at present has some probability of occurrence, admittedly small, but it is far from zero in its limiting sense. Hence, the Writer would like to know the details of flood warning systems installed, if any, in case of major floods, and the estimated probability of occurrence of the spillway design flood of 17600 cumecs.

61. The Writer would like to clear two more points. Firstly, why was a radial type of gate chosen? If it was to 'control the discharges passing the dam', perhaps drum gates would have been better. Secondly, on what basis was it decided to have the full rated output at a head of $29 \mathrm{~m}$ ?

\section{Mr H. Addison, Consultant}

I feel that the value of the two Papers would be still further enhanced if they were studied in relation to the evolutionary history of storage reservoirs in the Nile Basin. It is just 65 years ago that the original Aswan dam was inaugurated, forming the first storage reservoir on the river Nile. During the years that followed, dams have been built successively at Sennar on the Blue Nile, at Gebel Awlia on the White Nile, at the Owen Falls on the Victoria Nile, at Khashm el Girba on the river Atbara, and now at Roseires on the Blue Nile. Still under construction, but already operational, is the very much Jarger Aswan High Dam.

63. Within this period of development, remarkable advances in engineering technique have been fostered. In 1902, solid granite formed the first Aswan dam: at Roseires, concrete buttresses have been combined with earth embankments. The 
maximum flow controlled by one of the sliding sluice gates of the Aswan dam was of the order of 100 cumecs: at Roseires, each of the deep-level radial gates controls a discharge of 1480 cumecs. For protecting from erosion the river bed downstream of the dam, sloping glacis or aprons were used at Aswan, lip walls were installed at the Sennar dam, and the ski-jump type of apron was preferred at Owen Falls and at Roseires.

64. As for political changes in the Nile Basin in the twentieth century, the Authors point out in $\S 4$ of Paper 7047 that it was the revision of the 1929 Nile Waters Agreement that prepared the way for the Roseires Dam. While, according to the terms of this Agreement, the Sudan could only use $\frac{1}{12}$ of the total yearly flow of the River Nile, yet in the new Agreement of 1959 this share was increased to $\frac{1}{3}$. Moreover, one of the restrictive clauses of the earlier Agreement has been waived: it was the clause that limited the period during each year when Blue Nile water could be taken for the Sudan, to ensure that the filling of the Aswan reservoir should be in no way prejudiced. As can be inferred from the present Papers, no such restrictions are in force today, nor is the reason in doubt-the capacity of the enlarged Aswan reservoir is now so great that it can wholly absorb fluctuations in the flow of the Blue Nile, whether natural or artificial.

65. When trying to predict the long-term consequences of the Roseires dam-a rewarding exercise for the Authors-it would appear from the location map (Fig. 1, Paper 7047) that the population distribution in the Sudan will be quite sensibly affected; for the new Kenana project and the Wad el Ais project will accommodate many thousands of new settlers. Are the Authors aware of any overall development plans for these regions, comparable with those that were carried into effect in the original Gezira area? Since in these as yet undeveloped areas the natural rainfall is substantially greater than it is in the Gezira area, possibly a more economical pattern of irrigation may be devised for them.

66. At the moment, though, all the water released from the Roseires reservoir will presumably be utilized north of Sennar, that is, in the Gezira and Managil regions. Could the Authors therefore say whether these areas, depending on the canalization system fed from the Sennar reservoir, are already so extensive that they can utilize the full 2 milliards capacity of the first stage of the Roseires reservoir? In other words, is the new reservoir already earning its full potential revenue?

67. But however the irrigation water is apportioned, the operation of the 1959 Nile Waters Agreement and of the Blue Nile systems will depend on the accurate measurement of the water flowing past the Roseires Dam. It is in this connexion that the information given in $\S 76$ of Paper 7048 is significant. Seemingly the results of experiments on site did not always agree with experiments on scale models. Now in earlier comparative experiments on full-scale sluices and on models, carried out at Aswan and Sennar, there was quite good agreement, which assisted in the interpretation of other model studies. This correct interpretation was of fundamental importance, because it helped in the calibration of the sluice openings and thereby conferred on these dams the role of measuring devices of hitherto unexampled accuracy. In regard to $\$ 75$ and 76 of Paper 7048, then, could the Authors say whether the testing in question was directed to the calibration of the sluice openings in the Roseires Dam?

68. Another aspect of testing that the Authors mention is the observed prejudicial effect of opening a few gates fully in order to pass a specified discharge, as compared with partially opening all the gates. The resultant possibility of increased downstream bed erosion has been noted by other observers, including the Writer. This unequal distribution of water over the downstream river bed may have still more serious consequences during emergency conditions, for example, when one of the deep-level gates has to be closed $(\$ 21$, Paper 7047$)$.

69. Judging by the impressive dimensions of the deep-level radial gates only this type of gate would have been acceptable in these conditions. It would have been far 
more difficult to devise practicable flat sliding gates. Could the Authors say what kind of sealing system was chosen for the radial gates, both for the ends of the gates that work against the sides of the buttresses, and for the part-cylindrical surfaces?

Dr W. MacGregor, Director, George Wimpey and Co. Ltd

Both Papers constitute an excellent addition to the knowledge of design and construction of dams. In particular, the work which has been done on the black cotton soils is extremely valuable and the results from the trial embankment ( $\$ 60$, Paper 7047) will be of great interest to all engineers who are being faced with foundation problems on this particularly difficult soil. It is suggested that once results are available a follow-up paper might be presented to the Institution by the Authors. This could usefully include records of other measurements obtained from the instrumentation which has been described in Paper 7048 ( $\$ \S 78-97)$. The records from the acoustic strain meters on a few typical buttresses would be particularly useful because at present the Writer is extremely doubtful about the performance of such recording instruments.

71. In $\$ 61$ of Paper 7048 it is noted that the moisture contents during compaction were preferably above optimum in order to minimize the risk of cracking. Presumably, this refers to cracking due to settlement rather than drying out. Further data on the difference between the site results and model tests $(\$ 76)$ would be useful. Can the Authors give any reasons why the model tests did not give good agreement with practice?

72. Some data on the pumping capacity which was required to deal with leakage through cofferdams, etc., during the construction period would be most useful.

\section{Mr R. J. T. Casinader, Binnie and Partners}

The choice of a buttress dam for the main structure would appear to be unquestionably the correct solution at Roseires but it would enhance the record if the Authors would give their reasons for the choice of this type of dam rather than a concrete gravity dam. The latter solution is sometimes favoured where the cost of skilled labour is high compared with the cost of concrete-making materials, but presumably at Roseires the opposite was the case. Was the choice affected by the problem of temperature rise in the concrete (although in the event this appears to have been quite moderate)? A circumstance usually in favour of a buttress design is where an appreciable depth of excavation is required to obtain a sound foundation. To what extent was this advantage affected by the decision, reported in $\$ 21$ of Paper 7048 , to excavate to a general level in open cut? One factor in favour of a gravity dam may have been that acceptance of a lower standard of rock in the foundations, because of lower foundation pressures, may have saved the deeper trench excavation required for the buttresses, an argument which was used with respect to the transition sections (§ 22, Paper 7048).

74. In $\S 33$ of Paper 7047 the Authors state that at the lowest level of the $3 \mathrm{~m}$ web 'the horizontal water load is 0.88 times the vertical weight of the structure'. Would they please clarify whether this factor takes account of the vertical water load on the upstream face and the specified angle of inclination of the foundations and lift lines? (The uplift assumed would also be relevant.) If the factor of 0.88 quoted does take account of these effects, it is indeed unusually high for a 'sliding factor' and the reasons for the Authors' confidence in adopting this high value would be appreciated.

75. No mention is made of any keys or starter bars being left in the downstream face of the buttresses for future raising. Do the Authors intend that the cold joint on this plane when the dam is raised should merely be grouted? Presumably no keys were left in the web construction joints.

76. It is interesting to note from $\S 40$ of Paper 7048 that the depth of the grout curtain was specified in relation to the height of the dam rather than in relation to the watertightness of the rock. It is not clear, however, why a pressure at least equal to reservoir water pressure was not specified where water tests were carried out prior 
to grouting. Would the Authors care to comment further on these aspects and also say what criterion was used in the final water tests referred to in $\S 45$ to determine whether the grouting was satisfactory?

77. Finally, the figures in Table 5 of Paper 7047 show that due to siltation the useful life of the reservoir up to level 467 will be only 39 years, and one hopes that this is a conservative estimate. If in fact siltation does take place at the predicted rate how will the efficacy of the low level sluices and the spillways be affected? Do the Authors consider that the development of density currents will assist in reducing the rate of siltation, and have the low level sluices been located to make use of this effect?

\section{Mr A. E. Griffin, Consultant}

I would be glad if the Authors would indicate how they had arrived at the design flood of 17600 cumess. From what they say, the flood regulation would be on somewhat similar lines to that of Sennar, though at Roseires the degree of attenuation provided by the reservoir would be very much greater, allowing for peak discharges considerably higher than 17600 cumecs for a day or so at safe levels. Assuming a flood of 17600 cumecs and all sluices and spillways open, how long will it take to fill the reservoir to $481 \mathrm{~m}$ from the starting level of $467 \mathrm{~m}$ allowing for no irrigation and power demands?

79. Have the Authors been influenced by the design flood of 15000 cumecs used for the Sennar Dam? I wonder how this figure would compare today with one computed by hydrometeorological methods.

80. I do not wish to imply that the Roseires figure of 17600 is unsuitable but, having regard to its importance, $I$ feel that it merits more than the single sentence which is all the Authors have devoted to it.

81. From the general aspect of Nile control, it is interesting to observe that the reservoir, in addition to that of Sennar, can be filled on the falling flood without raising any difficulties with Egypt. This is one of the beneficial results of the High Aswan Dam, a project condemned by many engineers when it was first suggested.

\section{Sir Thomas Foy, Consultant, Haigh, Zinn and Associates}

Papers 7047 and 7048 are most interesting and instructive. The Authors are to be congratulated on the great amount of information presented. This contribution will discuss some aspect of the subsoil flow pattern shown by the observed values of the piezometers given in $\S 85$ and Fig. 17 of Paper 7048 .

83. The Roseires Dam consists of a control buttress dam between 800 and $900 \mathrm{~m}$ wide which contains the hydraulic control structures. This buttress dam is flanked by the east embankment $(4900 \mathrm{~m})$ and west embankment $(7800 \mathrm{~m})$ sections of conventional design with an impervious core protected by pervious shell sections.

84. The present river course lies along a rock ridge approximately $5000 \mathrm{~m}$ wide, the rock elevation varying from 454 to $468 \mathrm{~m}$. The rock level is inclined away from the river on both sides. It is overlaid on the flanks by sandy soils with about $8 \mathrm{~m}$ of upper clay at the surface. The rocks consist of metamorphic gneisses and granites, the former being deeply weathered and porous. The sands provide the shells and berms which have a permeability of $3 \times 10^{-3}$. The mean grain size was such as to pass a No. 40 B.S. sieve.

85. The structure thus rests on a pervious foundation. The buttress dam has been provided with a grout curtain (on its upstream side) going down to elevation 400 . This grout curtain was extended rather a short distance under the embankments on both flanks. Contact grouting was wisely provided round the foundations of the webs of the buttress dam. Drainage holes were provided at $12 \mathrm{~m}$ and $33 \mathrm{~m}$ downstream of the curtain.

86. The embankment sections were originally designed with broad upstream silt blankets, but during construction this was changed to a deep cut-off trench in the west high section. It would be of interest to know whether this change was dictated 
by economics or whether the deep cut-off was considered more efficient technically than the broad silt blanket. The embankments rest on porous decomposed rock or on the sands and are provided with relief wells.

87. Two lines of piezometers were installed under the concrete dam: the upstream line was immediately downstream of the buttress head and taken down to a depth corresponding to $25 \%$ of the second stage dam height above its foundations, while the second line near the toe of the dam was carried down to twice the depth $(50 \%)$ of the upstream line. In the case of buttress 21 (Fig. 17) the upstream piezometer screen was at elevation 415 with the hole extended to 410 . The downstream screen was at 400 with holes down to 394 .

88. In $\S 85$ it is stated that in a number of cases the downstream line of piezometers, which were at a greater depth, gave readings higher than the upstream ones, and it is also stated $(\$ 93)$ that there was seepage at the downstream toe. Since the ground level of the high section of the east embankment is at elevation 470, any seepage would arise from a stream tube with a piezometric level in excess of this, say about $470 \cdot 3$, so the level of the water table on the flanks downstream of the buttress dam grout curtain approximates to this.

89. The higher levels in the downstream piezometers as compared with the upstream ones can be due to:

(a) lateral subsoil inflow between the two lines from the high subsoil levels of $470 \cdot 3$ on the flanks, or

(b) a different distribution of subsoil flows and pressures from that given by the flow net, from which it is stated that the pressures were estimated.

The flow net is a graphical method of applying an assumed law of subsoil flow. While lateral inflow cannot be ruled out, the large increase in the relatively short length of $48 \mathrm{~m}$ would make this improbable as the main or only cause.

90. An alternative concept for the estimation of subsoil flows and pressures was examined by the Writer in 1942, based on observations made on Panjnad Barrage in the Indus system. This barrage was very fully instrumented, and the recordings were published by Khosla et al. ${ }^{\mathrm{D} 20}$ The examination was not then pursued further as the range of head in the Panjnad observations was small, and the Khosla rules were very suitable for the works then under consideration, i.e. barrages and weirs for low heads. The alternative may offer an explanation for the results observed at Roseires.

91. This alternative method may be described as the dominant stream tube method. When a dam is placed on a pervious aquifer it induces a head on the stream tubes under the dam. This diminishes from full head at entry to a low value near the downstream end. At any point along the tube the excess pressure may be expressed as a percentage of the total head and designated the residual pressure $\left(p_{\tau}\right)$. The dominant stream tube, having the highest $p_{\mathrm{r}}$ is that which dives just below the level of the upstream pile line or grout curtain and then flows approximately horizontally until it meets a second vertical obstruction (if any) taken down to a greater depth than the tube. After passing the most downstream of the vertical obstructions or the end of the impervious portion of the dam, the stream tube can be assumed to take an upward vertical path, losing excess pressure by diffusion.

92. $p_{r}$ was found to diminish along the upstream tube in accordance with the following relationships:

(a) during vertical downward flow on an outside obstruction

$$
p_{r}=\mathrm{e}^{-x}
$$

where $x=\log _{10} d / \log _{10} \mathrm{e}=0.434 \log d$

and $\quad d=$ depth below point of entry

(the reduction is independent of the nature of the soil);

(b) during the horizontal travel the loss follows Darcy's law and equals $K . L$ (at Panjnad $K=0.0021 \%$ of $h$ per foot of travel); 
(c) the diffusion loss is given by

$$
p_{r}=\mathrm{e}^{-\boldsymbol{K}, d},
$$

where $K$ depends on the soil and $d=$ distance above deepest level of the dominant stream tube. At Panjnad $K$ was approximately 0.054 . There is no direct evidence of its value at Roseires, but a value of $K=0.03$ gives fair agreement with the results observed on the upstream line of piezometers.

93. Applying this concept to the Roseires observations with horizontal loss equal to $0.0021 \% / \mathrm{ft}$ and diffusion $K=0.03$, we get:

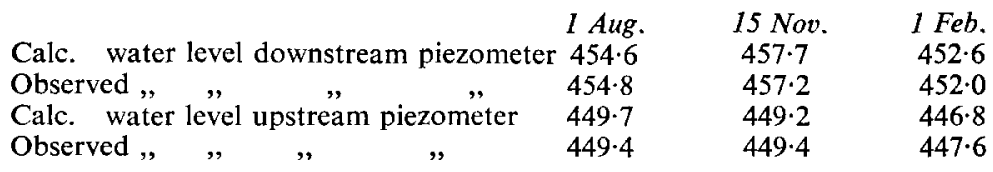

This agreement is tolerably good.

94. The higher levels on the downstream piezometer screen can be explained by lateral inflow from flank areas beyond the influence of the grout curtain: they can also be explained as being measured at a deeper stratum than in the case of the upstream piezometer screen where the pressures had been subject to loss by diffusion between the two levels. The alternative method of calculating piezometric pressures gives accurate results in the case of the downstream piezometers. The calculations for the upstream piezometers depend on the determination of the constant in the diffusion equation $p=\mathrm{e}^{-K d}$. There are no data available for determining $K$ for Roseires, but a value of 0.03 gives results close to those observed.

95. The higher levels in the downstream piezometers are not due to the local relief by drainage holes near the upstream piezometers: the Paper states that the provision of additional holes had little effect on the levels. It is very desirable that an acceptable reason be found for this phenomenon. If it is mainly due to lateral subsoil inflow, the conclusion could greatly diminish the desirability of upstream silt blankets and other items. If the alternative method of estimating subsoil flow is correct, this would affect future methods of designing.

96. It is suggested that the correctness of the alternative concept could be decided at Roseires at relatively small expense by the addition of another piezometer close to the downstream piezometer near buttress 21 , with its orifice at $415-410$, as for the upstream piezometer, to determine the validity of $p=\mathrm{e}^{-\kappa d}$ and the value of $K$.

97. It is further suggested that two additional piezometers be fixed $100 \mathrm{~m}$ downstream of the downstream piezometers, one on the buttress 21 line and one on the line through the deep sluices, to determine the diminution of pressures in a horizontal stratum downstream of the dam. The orifices would be at 400-394 as for the downstream piezometer screen.

Mr J. O. Robertson, Hydro-Electric Commission, Hobart

In $\S 11$ of Paper 7047 the Authors state that evaporation losses will be high, but the figures given in Table 1 indicate that they are not likely to be as great as one might expect, bearing in mind the high pan and Piche evaporation figures of up to $3 \mathrm{~m} /$ year found in the more arid parts of Sudan. No doubt the mean annual rainfall of about $750 \mathrm{~mm}$ helps to reduce the nett loss, although most of it will normally fall when the reservoir is low or filling up.

99. Would the Authors indicate the pan factors used to estimate evaporation losses? Presumably, variable monthly or seasonal values were used to take care of the wide variations in wind, temperature and humidity. Also, were site evaporation records available and if so, what instruments were used? Pan factors at the best of times are usually inspired guestimates, but in view of work carried out recently by the 
Writer in West Africa at a similar latitude, he would welcome further information on this subject.

100. In the design, was any consideration given to evaporation reduction by monomolecular films, polystyrene blocks or other devices? Problems such as the size of the reservoir, the large drawdown and inflow variations, plus the wind regime at certain times of the year would make control very difficult; nevertheless the Authors' comments on this would be welcomed.

101. Finally, no mention has been made of potential seepage losses. Even if the basin is 'tight', deep weathering of basin rocks and a low ground water table could absorb a considerable fraction of the useful storage, especially during the first two or three years of operation. Has this been allowed for, and if so, is it likely to be significant?

\section{Mr G. R. Curtis, North of Scotland Hydro-Electric Board}

Roseires Dam is of broadly comparable size to some of the larger gravity and buttress dams of the North of Scotland Hydro-Electric Board. Furthermore, Mullardoch Dam, which is $48 \mathrm{~m}$ high and $727 \mathrm{~m}$ long, also has a bend, of $60^{\circ}$, part way along its length, and certain comparisons might be justifiable.

103. At Roseires Dam a very satisfactory way of obtaining shorter ranges for collimating has been achieved by installing the collimator at the intermediate buttresses 10 and 57. From the small-scale plan given in Paper 7048 these ranges would appear to be about $100,140,150$ and $500 \mathrm{~m}$. Thus, with the related pendulums taken into undisturbed rock at buttresses 10, 21 and 57, a reliable zero datum is achieved, and the true movement of all buttresses is obtainable, it being very noteworthy that every buttress in the dam is observed.

104. Collimation on the dam crest and on the subsidiary line along the downstream face of the buttresses must be exposed to direct sunlight and I wonder if it has been found necessary to do much of this work at night.

105. Precise levelling is done by a levelling instrument and it will be interesting to know whether an accurate check on this could have been achieved by using invar wire for the pendulums, or whether, by hanging a secondary wire in the existing pendulum shafts, this could still be done. The use of invar pendulum wires has been undertaken in some of the Board's dams but it is too early to analyse results from the recent installations.

106. It would appear that when the collimator has been set up and aligned at Roseires Dam it is not touched by the operator until the series of observations has been taken, presumably one value being read for each buttress. It is, however, our experience, developed fom the Italian techniques, that there are many inherent errors in any single setting, not least that due to the bias of an operator in observing a mobile target moving into line, or in swinging the collimator into the line of the fixed target, as well as to the general instability of the atmosphere (except perhaps in the galleries). Our practice is therefore to take eight readings on the mobile target and to displace the telescope and recollimate on the fixed target every time. The mean of the eight readings is then calculated, and twice the standard error of the mean gives a measure of the reliability to be placed on the accuracy of the observations. This is usually within $\pm 0.8 \mathrm{~mm}$, but a further refinement in our system on a standard dam layout is to observe all targets from both ends and to average 16 readings. This 'double ended' system gives accuracies within $\pm 0.4 \mathrm{~mm}$ up to a range of about $500 \mathrm{~m}$.

107. Although the results from the inverted pendulums may not be very consistent (\$ 84), presumably the pendulums themselves are reliable instruments. The Board is obtaining excellent results from six oil-filled inverted pendulums, to one of which an automatic recording camera has been coupled.

108. In $\S 83$ (Paper 7048) it is stated that the buttress heads moved downstream by amounts up to $7.0 \mathrm{~mm}$, which seemed to be related to foundation conditions, 
during filling of the reservoir between July and November 1966. Unfortunately, no reference is made to concrete temperatures, but if they were rising during this time the downstream movement of the buttress heads due to hydrostatic loading alone would be greater than the movement indicated by the instrumentation results quoted, and of course falling temperatures would produce the opposite. From our experience this thermal movement might be of the order of $3 \mathrm{~mm}$ for a $5^{\circ} \mathrm{C}$ rise in a dam $50 \mathrm{~m}$ high. As thermal movements may well be of the same magnitude as hydrostatic movements it would be very interesting if the Authors could give temperature records over the period of impounding. From a study of the movement plot in Fig. 16 there is, I think, significant movement due to temperature as well as movement due to load.

\section{Mr W. N. Allen, Consultant in irrigation}

The Authors of both Papers are to be congratulated on such clear and concise presentations of the many and complex aspects of this highly important work. I have a close personal interest in it, particularly because just 30 years ago, my then chief, Mr A. N. M. Robertson and I reconnoitred the Blue Nile from Roseires to the border of Ethiopia, and chose the sites for five river gauges to provide data of local variations in water levels at significant points. One of these was close to the line ultimately chosen for the dam.

110. The construction of the Roseires Dam for annual storage by the Sudan, with also the construction of the High Aswan Dam primarily for over-year storage by Egypt, was included in the provisions of the Nile Waters Agreement of November 1959 between the two countries, which also settled their respective shares in the present flows of the Nile, agreed to be $18 \frac{1}{2}$ milliards of cu. $m$ for the Sudan and $55 \frac{1}{2}$ milliards of cu. $\mathrm{m}$ for Egypt, both amounts as at Aswan, subject to certain adjustments in case of future long-term variations in flows.

111. Compared with the total share of $18 \frac{1}{2}$ milliards (equivalent to about $20 \frac{1}{2}$ milliards at Roseires), the effective capacity of Roseires reservoir as now built is about 2.4 milliards; the corresponding figure when it is raised to reservoir level $490 \mathrm{~m}$ will be about 7 milliards. These figures illustrate the major importance of the Roseires reservoir in the development of irrigation in the Sudan, and particularly from the Blue Nile and its tributaries. Of land, suitable in quality and accessible to irrigation, there is more than enough; the limiting factor in development will be water. Efficiency in its use is therefore of prime importance.

112. In operation, the regulation of Roseires reservoir will at all times have to be closely co-ordinated with that of Sennar reservoir, some 150 miles downstream. To limit so far as possible the deposition of silt from the heavily laden flows in the high flood season, the main fillings of both reservoirs are deferrid until the annual flood begins to fall, and the silt loads to diminish. But it is essential also to begin these fillings at such a stage of river flow that the subsequent rapidly but irregularly diminishing flows will still suffice both to meet the current needs of irrigation, and to complete the fillings of the reservoirs, before the date of shortage when it becomes necessary to draw on the stored water. This is only one of the varying contingencies for which provision has to be made in comprehensive regulation rules, devised to guide the staff concerned with operation, so that the working of the reservoirs may be timely and effective for irrigation and for the generation of power, with constant regard, of course, to the safety and good maintenance of the structures.

Mr A. F. Reynard, Geustin. Forsyth and Joubert, Pretoria

I would be grateful if the Authors could outline the precautions and organization for maintaining the health of the workers, with special reference to malaria, bilharzia and heat stroke. A comparison would be valuable with Kariba Dam, which was also built in an arduous climate, by the same contracting firm, supervised by the same consultants. 


\section{Messrs Fitt, Marwick, Whitaker and Corney}

A small point raised by Mr Antonioli related to the labour forces. It will be seen from Fig. 20 of Paper 7048 that a major secondary benefit is brought to developing countries like the Sudan by the construction of major civil engineering works. At Roseires as the job progressed the percentage of skilled to unskilled men steadily increased and also, during the third and fourth seasons when the job was at its peak, there was also a very marked increase in the proportion of local labour as compared with the expatriates brought to the Sudan from Europe.

115. It has been mentioned that though the dam is built the openings in the dam still remain closed. This is perfectly true. The Sudan is incapable of carrying out more than a certain volume of work at any one time and in this stage of its development is very much dependent on assessments from international finance. This is why the scheme is going stage by stage. The installation of the first three machines will shortly proceed in the power house. There will in all be seven $30 \mathrm{MW}$ machines.

116. Mr Blackmore rightly points out the dangers that may result from a dependence on one source of electricity in dealing with a flood of $17600 \mathrm{cu} . \mathrm{m} / \mathrm{s}$. Firstly he may not have noticed that the roadway surface on the embankment is higher than that on the concrete dam, giving a further $\frac{1}{2} \mathrm{~m}$ factor of safety, and there is also the wavewall on the high section to give added protection. With regard to safety, there are two sources of electricity, a diesel generating station in the township and the service power house on the dam; there are also diesel standby sets provided in case of failure of electricity, and in the last resort, hand operation is possible.

117. Power development from the Roseires dam will take second place to irrigation. It is an irrigation dam. As has been pointed out, the irrigation pattern does give the opportunity for power development. The price we pay is the loss of kilowatt capacity at times of high flood when the head is low and a loss of units when the discharge is low. In assessing the economics of such a scheme it is essential to consider the associated thermal plant, which here is in Khartoum, and the cost of the transmission line.

118. A point was raised about the possibility of providing much larger storage in the Sudan. This does not appear to be possible there but it may be possible higher up the system in Ethiopia. The storage which is provided in the High Aswan reservoir can be of benefit to the Sudan, given mutual goodwill. In extremely dry years Egypt, with her vast storage in the High Aswan reservoir, might be able to permit the abstraction of more of the water in the Sudan than would otherwise be the case. What is proposed now is certainly covered by international agreement between the Sudan and Egypt.

119. $\mathrm{Mr}$ Seddon has asked about the design and construction of the buttress dam. The upstream face of the buttress dam was reinforced with a mesh of steel varying from $1 \frac{1}{2}$ in. dia. at $10 \mathrm{in}$. centres horizontally and $1 \mathrm{in}$. dia. at $20 \mathrm{in}$. centres vertically at the base, to $1 \mathrm{in}$. dia. at 14 in. centres horizontally and 1 in. dia. at 40 in. vertically at the top of the buttresses. This steel was extended downstream behind the bitumen seal. Slight tensions were anticipated on the face of the buttresses. Varying assumptions on uplift pressures were made depending on the location of the structure. Certain parts are always deeply submerged on the downstream side and others are in a zone of varying level. In all cases $100 \%$ uplift was assumed at the upstream side. Splays at changes of section in the buttresses were avoided for this dam, but are not considered unnecessary for all cases. Heights of lifts were halved on resumption of work after a seasonal stoppage.

120. $\mathrm{Mr}$ Seddon also asked about the height of lift after a pause in the concreting. The answer is that a reduced height of lift was required after a pause. In this case the standard lift was split into three with $48 \mathrm{~h}$ between the three parts of the lift. Some additional reinforcement was also placed to control any tendency to cracking of the new concrete. 

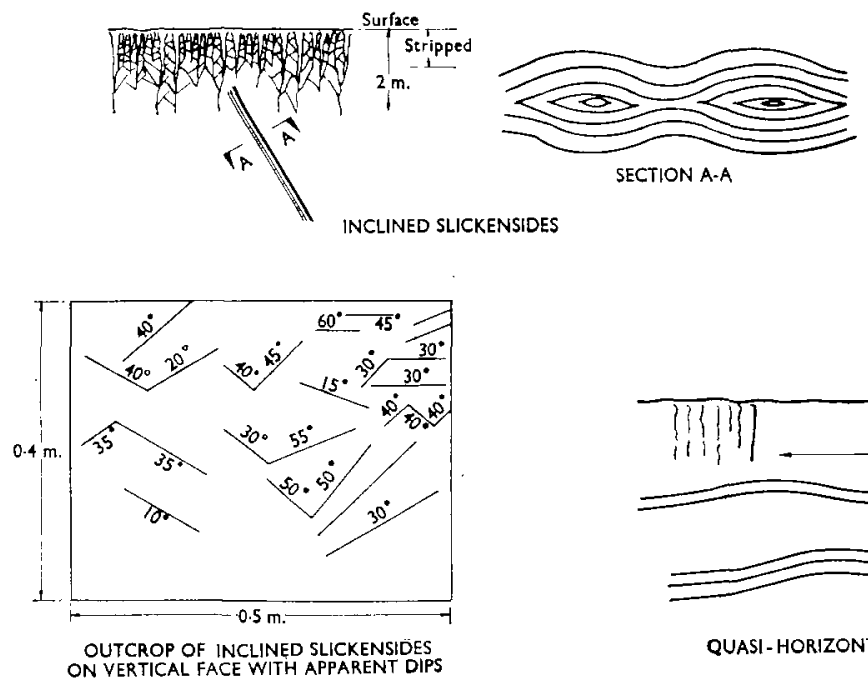

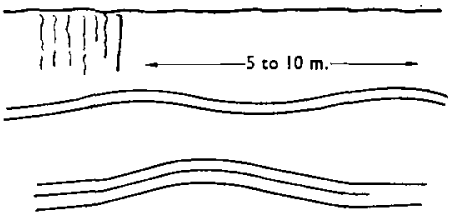

QUASI - HORIZONTAL SLICKENSIDES

Fig. D4

121. Mr Seddon also asked about the payment for variation in cement content. The Contractor was required to price additional items for increases and reductions in the cement content and the prices were so fixed as to provide an incentive to use a reduced cement content. The mixes were designed by the Consulting Engineers in conjunction with the Contractor, with a view to keeping the cement content as low as possible consistent with satisfactory strength in order to reduce the total heat of hydration. In fact, we managed to save a total of about $£ 50000$ by reducing the cement content below that specified for the standard mixes.

122. The use of bentonite in cement grouting has been mentioned. We have found on various sites that although bentonite slightly decreases the strength of the grout, the addition of a small percentage materially assists the penetration and helps to retain the cement particles in suspension. Unless there are going to be several re-injections where large quantities of grout are injected, the use of bentonite certainly assists in improving the watertightness of the treated ground.

123. Mr Lane has commented that overconsolidation may have been due to a higher land surface which has been eroded away. This may be true, but it is also due to desiccation, which is shown by the greater density of the top of the clay and by its capacity to swell. The swelling pressure, i.e. that at which there is neither settlement nor swelling, is in excess of $1 \mathrm{~km} / \mathrm{sq}$. cm. Fig. D4 shows the two forms of slickensides. These are possibly a result of some cause other than movements due to general relief of overstress from a higher land surface.

124. Figs D5 and D6 show changes in the crest levels of the two embankments. The crest of the east embankment, where the core is founded on rock, has settled. That of the west embankment, however, has risen. This is because the swelling of the foundation clay has exceeded the consolidation of the core.

125. The important thing in instrumentation is to make certain that changes do not progress to the point at which they would be dangerous. One is looking for unusual movements.

126. Mr Penman asked for the cost of instrumenting the embankments. Equipment had cost approximately $£ S 10000$ ex-works and $£ S 14850$ delivered to site. 


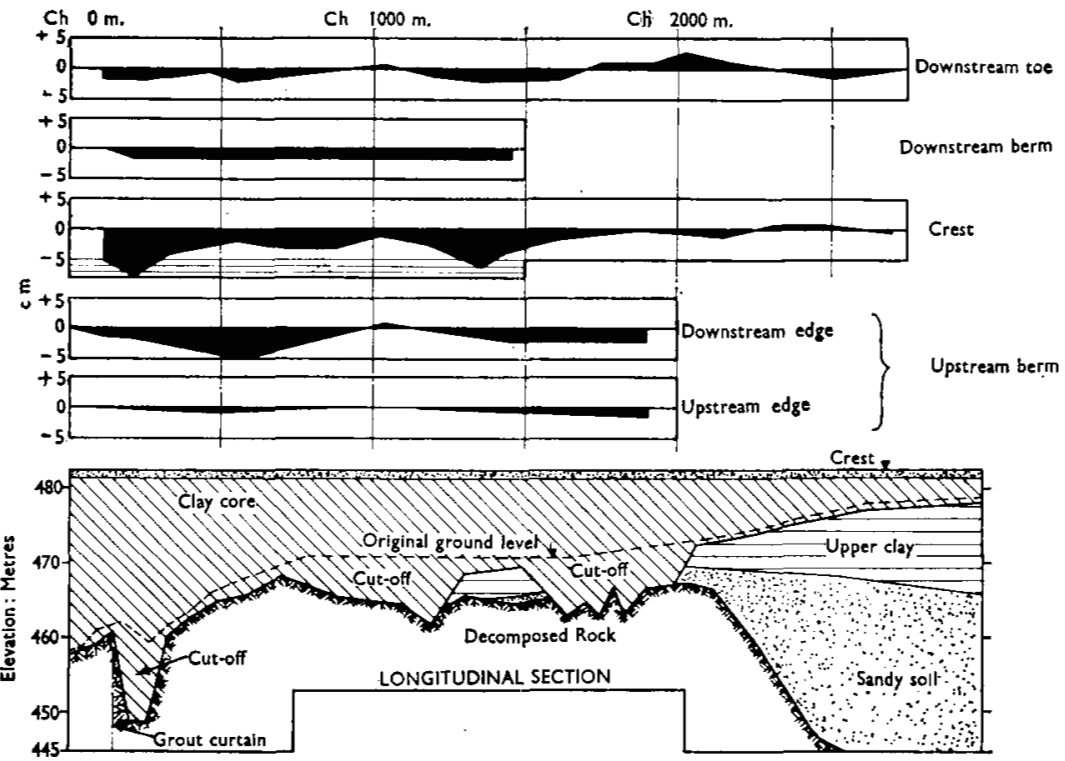

Fig. D5. Changes in level at 15 January, 1967: east embankment
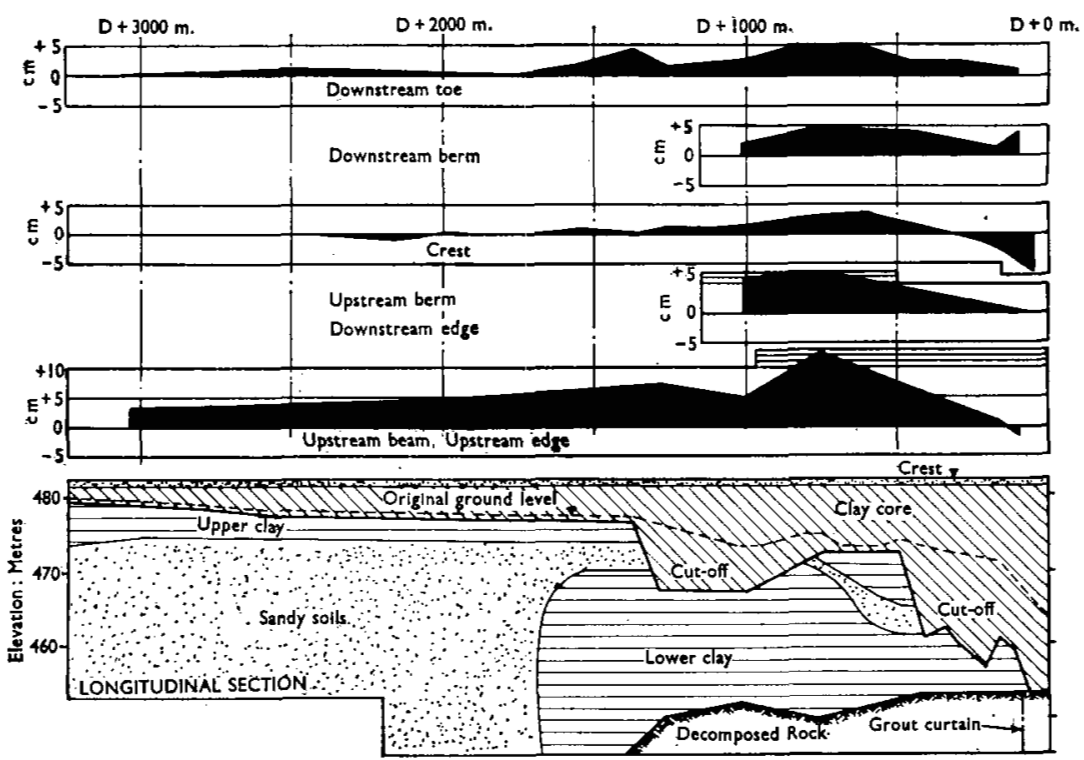

Fig. D6. Changes in level at 4 January, 1967: west embankment 
Installation, gauge houses and survey stations amounted to $\mathfrak{A S} 11500$. The total was equivalent to $0.86 \%$ of the cost of the embankments or to $0.9 \%$ if the costs of the low sections, which were not instrumented, are excluded.

127. Mr Macdonald raised questions about the movement control survey. Two of the pendulums (at buttresses 10 and 21) were single inverted pendulums with the wire fixed in a borehole approximately $20 \mathrm{~m}$ deep. The oil bath and float were housed in a chamber in the buttress just below road level; the wire was housed in an asbestos pipe fixed to the side of the buttress. It would therefore have been possible to observe the wire at foundation level as well as at the crest but this was not considered necessary. The pendulum at buttress 57 is a double pendulum having both the float chamber of the inverted pendulum and the plumb bob of the normal pendulum which hangs from the crest housed at ground level. Unfortunately, due to delivery difficulties, the pendulums were not operating during the first impounding but since then they have provided a useful check on the triangulation results.

128. In order to simplify the reading and recording of results the whole triangulation scheme was kept as simple as possible. Mr Macdonald is correct in saying that this involves a risk in the event that any of the downstream stations being damaged, but with well-protected stations and the use of the pendulums we considered such a risk acceptable:

129. The triangulation stations downstream of the earth embankments presented considerable problems due to the very great depth of clay which was subject to considerable surface movement caused by desiccation and cracking. We were not satisfied that a large monolith would constitute a fixed point and therefore a borehole was drilled through the upper clay and a stiff pipe concreted in at the bottom and allowed to stand freely inside the borehole casing. This has provided a satisfactory fixed reference point over which the theodolite or target could be set up.

130. Mr Searle mentioned loss of storage due to accretion. The main points in the consideration of loss of storage are given in Appendix 2, but by no means all.

131. With regard to Mr Searle's other comments, model tests were not specifically related to reservoir siltation, the method of operation of the reservoir being the most important factor. The data on silt at Sennar were certainly used in consideration of the problems involved, in conjunction with other data from Aswan.

132. Mr Dixon's use of the unconfined compression test for compaction control is interesting and,worthy of further trial, particularly where the as-constructed strength is a critical factor in the design. The strength for the peak of the B.S. compaction curve can also be attained with lesser compaction if the moisture content is below optimum and this method thus shares with the single point method described by Mr Matthews the prerequisite that the moisture content is not significantly below the optimum. That condition can, however, usually be judged by the feel of the soil. Mr Dixon's method might also be used with a maximum unconfined compressive strength to safeguard against excessively dry compaction producing a core which is prone to cracking.

133. Regarding Mr Zolkov's queries: the USBR Rapid Compaction Control Method was tried in the compaction test embankment but it was regarded as being too complicated, too slow and not entirely suitable for the black cotton soil. Full B.S. tests were used in the first season.

134. The results from the first season were used to draw a statistical control chart which had bands indicating the probable percentage of relative compaction for a dry density plotted against its moisture content. Acceptance or rejection of a batch of results depended on how the points and their average were related to these bands. This chart was, however, abandoned in favour of the one-point method described by Mr Matthews, together with full B.S. tests carried out at a reduced frequency.

135. The dual method of control produced the following median percentages of B.S. standard relative compaction for various lengths of the core: $99 \cdot 5,97 \cdot 7$, $104 \cdot 5,100 \cdot 8,99 \cdot 8$ and $103 \cdot 8$. The accompanying values of standard deviations were 
$5 \cdot 0,4 \cdot 0,5 \cdot 0,5 \cdot 0,8 \cdot 0$ and $4 \cdot 1 \%$ respectively. The following are examples of the frequency of occurrence of $90 \%$ and $95 \%$ relative compaction.

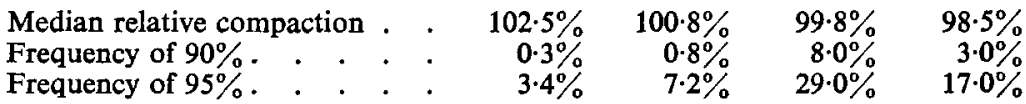

136. The maximum deviations of gas-burner moisture contents from their mean relationship to oven-dried moisture contents were $\pm 1 \%$ but the majority of the deviations were less than half this figure.

137. Dr Biswas raised some questions on the hydrology and water resources engineering. The peak discharges recorded in 1946 are based on observations at Sennar Dam and gaugings upstream of Sennar Reservoir. It is not possible to gauge their absolute accuracy, but the presence of the Sennar Dam ensures that they are closer than gaugings on a completely uncontrolled river of large size.

138. The major part of the Blue Nile catchment above Roseires is in Ethiopia, and past records of all meteorological data are extremely limited. Present opportunities for flood warning arise only from a gauging station on the Sudanese side of the border, and communication is maintained with Roseires by radio.

139. The radial type of gate was chosen as the one most suited to controlling flows of up to 1500 cumecs per gate over a wide range of operating conditions, as economically as possible within the planning restrictions of the site and the method of construction of the dam.

140. Although the emergency gate hoist is designed to be capable of cracking the gate against unbalanced pressure, it is not the intention that it should be operated in that manner, except in emergency.

141. The future turbines will be required to operate under a very wide range of head from 17 to $47 \mathrm{~m}$. The buttress spacing places a physical limit on the size of an individual turbine and the number of turbines is limited by the general planning of the layout and method of construction. If a lower head were adopted as a criterion for full output, then there would be a loss of energy, unless further sets could be incorporated in the dam.

142. With regard to $\mathrm{Mr}$ Addison's queries, there is immediate use for stored water in Roseires reservoir in extensions to the Managil scheme, intensification of cropping in the Gezira and in the removal of restrictions on watering of pumped irrigation. Development of new areas is under consideration at present.

143. Model testing of the gates was directed largely to calibration. The differences referred to in $\$ 76$ of Paper 7048 relate to operating conditions for the gates, not to calibration.

144. A synthetic rubber 'music note' type seal was used for both the sides and lintel seal of the radial gates. In the case of the lintel two seals were provided, one mounted on a flexible plate to accommodate to the curved face of the gate at intermediate openings and a second to close against the lintel in the shut position. The leakage past side and lintel seals has been negligible; some tearing of the bottom seals has occurred due to impact from submerged debris but it is hoped to overcome this to some extent by using a seal reinforced with nylon cord.

145. Dr MacGregor is correct in assuming that the designers had envisaged risks of cracking due to causes other than drying out. These were:

(a) differential changes in crest level due to consolidation of the core and swelling of the foundation clay, which would vary with the different heights and depths respectively;

(b) downstream movement of the crest following impounding, which would tend to put the core in tension around the bends of the embankment and in shear at the transitions. 
Cracking due to drying out has, however, also been considered. The thickness of sandy soil cover over the core was decided after a lengthy period of trials on the compaction test embankment.

146. Mr Casinader raised several queries. The buttress type of dam was chosen to reduce the volume of concrete to be handled in a limited time, and also to limit the temperature rise in the hot climate. Excavation to a general open cut level was adopted as a means of speeding up the work, and limiting the depth of trenches in weak weathered rock.

147. The minimum depth for the grout curtain was $h / 3$. Instructions for grouting included provision for extending the curtain based on the grout acceptance in the lower stages and on the final water tests in the holes. There is an error in the Paper regarding the water test pressure which was $10 \mathrm{~atm}$ at the top of the hole-since most holes were drilled from level 430 or above this is considerably in excess of the reservoir water pressure.

148. The criteria for considering the grouting complete were that the water absorption of a grouted hole should not exceed $0.15 \mathrm{l} / \mathrm{min}$ per $\mathrm{m}$ measured over the complete hole at a pressure of $7.5 \mathrm{~atm}$. For an ungrouted test hole drilled in the line of the curtain the criterion adopted was $2.5 \mathrm{l} / \mathrm{min}$ per $\mathrm{m}$.

149. The figure of 39 years for siltation of the reservoir up to level $467 \mathrm{~m}$ is a conceptual one. The silt will be deposited in various parts of the reservoir and in 39 years may reduce the volume by the equivalent of the capacity up to $467 \mathrm{~m}$ level. The operation of the gates should keep their approaches clear and their behaviour should remain largely unaffected.

150. With regard to Mr Griffin's comments, flood attenuation at Roseires is comparatively small. The capacity of the reservoir between levels $467 \mathrm{~m}$ and $481 \mathrm{~m}$ is about 2.4 milliards. An inflow of 17600 cumecs could fill the entire volume, assuming no outflow, in under $40 \mathrm{~h}$. Hence the requirement of keeping the reservoir at as low a level as possible during the flood.

151. The estimate of design flood flow is that based on a study of limited meteorological information and a unit hydrograph analysis, with supporting geological information from a study of old flood marks in the Sudan and Ethiopia. A study of previous records would support the figure of 15000 cumecs which was adopted for the Sennar dam.

152. The variable nature of the foundation rock and overlying beds would greatly reduce the value of the methods suggested by Sir Thomas Foy. Simplified assumptions considering local flows in two dimensions can also lead to the result that downstream piezometer levels can be higher than upstream ones.

153. Mr Robertson has asked about evaporation losses. Evaporation losses are estimated as $75 \%$ of Piche values, varying throughout the year. No pan evaporation tests were carried out. The reservoir area and its rapid fluctuations of level are unfavourable for evaporation reduction by surface treatment, at least in the present state of that art. Since the full demand for water requires some years of development, early losses of water by infiltration have been ignored. Present indications are that they are comparatively small.

154. Mr Curtis's method of using the collimator is undoubtedly superior but for reasons mentioned above we were satisfied with reading all targets from each end of the collimation line with only one set up of the collimator.

155. Regarding Mr Reynard's query, the Contractor at Roseires was responsible for the staffing and operation of the hospital and public health services. Roseires is a malarial area and there are considerable numbers of anopheles mosquitoes during and after the rainy season. It was planned that the Contractor would be responsible for malaria control but in the event Roseires was designated as a malaria eradication area by the World Health Organization and all spraying and control measures came under their supervision. Daraprim was issued to all ex-patriates but WHO would not agree to its issue to the local population. 
156. Bilharzia is not present in the Blue Nile at Roseires and the only cases found were among immigrant workers from the South.

157. Heat stroke was not a problem despite the high temperatures. The position was probably alleviated by the wearing of white safety helmets on the site.

158. Comparisons with Kariba are difficult since at Kariba the Rhodesian Government equipped and staffed the hospital and in addition a programme of aerial spraying was carried out before construction started. Such a programme was essential at Kariba and in the event incidence of malaria was very low. Malaria was much more prevalent at Roseires, especially among local population living in adjacent villages, but modern methods of treatment prevented any disruption of the work.

\section{References}

D1. Casagrande A. Role of the 'calculated risk' in earthwork and foundation engineering. (Terzaghi Lecture.) Proc. Am. Soc. civ. Engrs, 1965, 91, SM4 (July) 24-40.

D2. FELLER W. An introduction to probability theory and its applications, Vol. 1. John Wiley \& Sons, Inc., New York (2nd edn) 1957, 7-8.

D3. Biswas A. K. and Fleming G. Floods in Scotland: magnitude and frequency. Wat. \& Wat. Engng, 1966, 70 (June) 246-252.

D4. Alexander G. N. Flood flow estimation, probability and return period. J. Instn Engrs, Austr., 1957, 29 (Oct.) 263-278.

D5. Benson M. A. Discussion: Hydrology of spillway design: large structuresadequate data. J. Proc. Am. Soc. civ. Engrs, 1964, 90, HY5 (Sept) 297-300.

D6. Hounam C. E. Estimation of extreme precipitation. J. Instn Engrs Austr., $1960,32$.

D7. US WEATHER BUREAU. Interim report: probable maximum precipitation in California. Hydrometeorological Report No. 36, US Department of Commerce, Washington, D.C., October 1961.

D8. Alexander G. N. Discussion: Hydrology of spillway design: large structure - adequate data. Proc. Am. Soc. civ. Engrs, 1965, 91, HY1 (Jan.) 211-219.

D9. Alexander G. N. Flood estimation in Australia. Bull. Austr. Nat. Comm. Large Dams, No. 16, July 1965, 27-40.

D10. ACKERMANN W. C. Application of severe rainstorm data in engineering design. Bull. Am. Met. Soc., 1964, 45 (April) 204-206.

D11. Alexander G. N. Application of probability to spillway design flood estimation. Proc. Int. Symp. Floods Computn, Leningrad, August 1967.

D12. Biswas A. K. Risk criteria and flood estimation. Hydrology Lecture Notes, No. 1, Queen's University, Kingston, Ontario, Canada, 1967.

D13. Biswas A. S. Discussion: Research needs in surface-water hydrology. Proc. Am. Soc. civ. Engrs, 1965, 91, HY5 (Sept.) 285-286.

D14. Biswas A. K. Discussion: Comparison of methods of flood estimation. Proc. Symp. River Flood Hydrology, Institution of Civil Engineers, London, 1966, 32-34.

D15. Gruner E. Dam disasters. Proc. Inst. civ. Engrs, 1963, 24 (Jan.) 47-60.

D16. Gruner E. The mechanism of dam failure. Int. Com. Large Dams, 9th Congress, Question 34, Report 12. Istamboul, 1967, 197-205.

D17. HershField D. M. Estimating the probable maximum precipitation. Proc. Am. Soc. civ. Engrs, 1962, 87, HY5 (Sept.) 99-116.

D18. Hershfield D. M. Extreme rainfall relationships. Proc. Am. Soc. civ. Engrs, 1963, 88, HY6 (Nov.) 73-92.

D19. Yevdevich V. M. Flood characteristics and spillway design. 10th Congress, Int. Assoc. Hydraulic Research, London, Vol. 2, 1963, 57-64.

D20. Khosla A. N. Design of weirs on permeable foundations. Central Board of Irrigation, Publication 12, Simla, 1936. 